\title{
Thermal modelling of cooling tool cutting when milling by electrical analogy
}

\author{
F.Benabid $^{1}$, M.Arrouf ${ }^{1,1}$ M.Assas ${ }^{2}$ and H.Benmoussa ${ }^{2}$ \\ ${ }^{1}$ Faculty of Science engineering, Department of electrical engineering, U.Batna, 05000, Algeria \\ ${ }^{2}$ Faculty of Science engineering, Department of mechanical engineering, U.Batna, 05000, Algeria
}

\begin{abstract}
Measurement temperatures by (some devises) are applied immediately after shut-down and may be corrected for the temperature drop that occurs in the interval between shut-down and measurement. This paper presents a new procedure for thermal modelling of the tool cutting used just after machining; when the tool is out off the chip in order to extrapolate the cutting temperature from the temperature measured when the tool is at stand still. A fin approximation is made in enhancing heat loss (by conduction and convection) to air stream is used. In the modelling we introduce an equivalent thermal network to estimate the cutting temperature as a function of specific energy. In another hand, a local modified element lumped conduction equation is used to predict the temperature gradient with time when the tool is being cooled, with initial and boundary conditions. These predictions provide a detailed view of the global heat transfer coefficient as a function of cutting speed because the heat loss for the tool in air stream is an order of magnitude larger than in normal environment. Finally we deduct the cutting temperature by inverse method. Key words: cutting tool cooling, equivalent thermal resistance, inverse method, milling, cutting temperature.
\end{abstract}

\section{Nomenclature}

$V_{c}$ : cutting speed $\quad \mathrm{m} / \mathrm{min}$

$P_{\text {tot }}$ : cutting power $\quad W$

$f$ : feed per tooth $\quad \mathrm{mm}$

$P_{\text {diss }}$ : dissipated power in the tool

$a_{e}$ : radial depth of cut $m m$

$t$ : time in seconds

$a_{p}$ : axial depth of cut $\mathrm{mm}$

$t_{f}$ : duration (end milling and shutdown) $\mathrm{s}$

$d$ : tool diameter $\quad \mathrm{mm}$

$T_{c}$ : cutting temperature

K

$e$ : disc thickness

m

$S_{l}$ : lateral surface of disc

$m^{2}$

${ }^{1}$ karrouf@hotmail.com

This is an Open Access article distributed under the terms of the Creative Commons Attribution-Noncommercial License 3.0, which permits unrestricted use, distribution, and reproduction in any noncommercial medium, provided the original work is properly cited. 


\begin{tabular}{|c|c|}
\hline$S_{f}:$ cross section of disc & $P_{d i s s}:$ dissipated power in the tool $J / K g . K$ \\
\hline$v:$ volume of disc & $K_{t o t}:$ global heat coefficient $W / m^{2} K$ \\
\hline$D:$ machined mater stream flow $\mathrm{mm}^{2} / \mathrm{s}$ & $E_{s}:$ specific energy $W \mathrm{~s} / \mathrm{mm}^{2}$ \\
\hline$T_{\text {meas }}:$ the first relevant of temperature $K$ & $\beta i:$ Biot number \\
\hline$T_{\infty}:$ ambient temperature & C: specific heat capacity $\quad J / K g . K$ \\
\hline$\lambda:$ thermal conductivity & $\mathrm{Kg} / \mathrm{m}^{3}$ \\
\hline$M:$ mass of disc & $\tau:$ constant thermal time \\
\hline$R_{e q}:$ equivalent resistance $m^{2} K / W$ & $R_{c}$ : convection resistance of disc $m^{2} K / W$ \\
\hline$R_{d}:$ conduction résistance of disc $m^{2} K / W$ & $R_{c 0}:$ cross convection resistance $m^{2} K / W$ \\
\hline$R_{c 0}:$ cross convection resistance $m^{2} K / W$ & $h$ : convection heat coefficient $W / m^{2} K$ \\
\hline$h^{\prime}$ : convection heat coefficient $\quad W / m^{2} K$ & \\
\hline
\end{tabular}

\section{Introduction}

Heat has critical influences on machining. To some extent, it can increase tool wear and then reduce tool life, get rise to thermal deformation and cause environmental problems $[1,2,3]$.

Due to the complexity of heat problem in machining, the following assumptions are generally imposed: First, almost all (90\%-100\%) of the mechanical energy consumed in a machining operation finally convert into the thermal energy [2]. Second, there are three major sources of thermal in milling: plastic deformation in the so-called primary zone and secondary zone, and the frictional dissipation energy generated at the interface between tool and chip, part of heat may be generated at the interface between tool and workpiece due to friction, Figure1.Third, even with the above assumptions, the problem of estimating the mean temperatures on the shear plane and tool face is complex. This is because part of the thermal energy will be converted away by the chip; part will conducted into the work piece and tool, i.e., a partition criterion is needed:

The measurement and prediction of temperature in tool cutting in (interrupted) milling is very important due to the phenomenon of ventilation during machining. In addition, the geometry of the tool, chip and work piece as well as boundary conditions are simplified to some extent.

The formation of a carter on the rake face of the tool will start in the region of higher temperature and the maximum is not on the point of tool [4].

This is why the thermal of machining becomes an emergent subject as testify many authors in this field.

In this paper, we thus will present a new modelling allowing describing cooling (fall) in temperature according to time in final phase, except matter, during the release of the tool.

We propose in this model, to improve it by taking of account the power dissipated by the tool, by means of thermal resistances (by conduction and convection) in a cylinder, who utilize the coefficient of transfer of heat by convection according to the cutting speed, with an aim of putting in place a more complete model and nearer of physical reality for the cutting tool at the time of an operation of milling.

\section{Estimation of the total power due to milling}

In an operation of milling, the temperature of the edge of cut increases according to the duration of the milling and cutting speed [5]. Energy necessary to the operation is provided by the spindle and can be determined by the measurement of the torque and number of revolutions.

This evacuated energy will have for principal effect to appreciably raise the temperature of the workpiece, the chip and the tool in the zones close to the edge of cut. Thus, the material undergoes a 
local heat treatment (surface hardening) which modifies the characteristics of the finished part. Many researchers tried to specify the division of the quantity of heat released between the three zones. For cutting speeds higher than $50 \mathrm{~m} / \mathrm{min}$, the greatest part is evacuated by chip, a fraction of $10 \%$ moves towards the tool and the remainder goes towards the workpiece.

Being given that thermal conductivity depends on time according to a linear function, heat cannot be completely dissipated; there is then on the rake face an accumulation of heat which supports the formation of wear in crater [2].

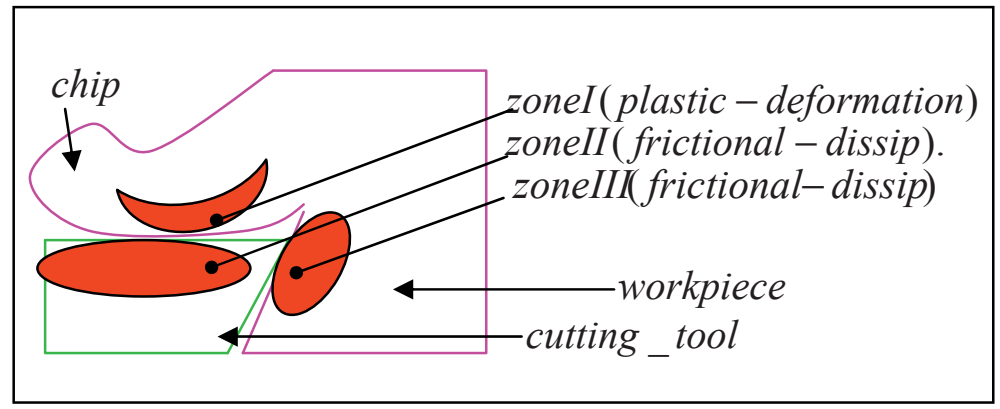

Fig.1. Major sources of thermal in milling.

Table1. Choise of cutting conditions

$$
\begin{aligned}
& V_{c}=400 \mathrm{~m} / \mathrm{min} \quad a_{e}=1 \mathrm{~mm} \\
& d=10 / 1000 \mathrm{~m} \quad a_{p}=5 \mathrm{~mm} \\
& e=1 / 1000 \mathrm{~m} \quad f=2547 / 60 \mathrm{~mm} / \mathrm{s} \\
& \lambda_{C T}=174 \quad(W / m K) \text { (tungsten carbide) } \lambda_{C}=100(\mathrm{~W} / \mathrm{mK}) \quad \text { (cobalt) } \\
& E_{s}=4.5 \mathrm{Ws} / \mathrm{mm}^{3} \\
& P_{t o t}=D \cdot E_{s}=66.859 \mathrm{~W} \\
& P_{\text {diss }}=10 \% P_{\text {to } t}
\end{aligned}
$$

\section{Estimation of the cutting tool temperature 31 Concept of thermal resistance}

An electric resistance is the relationship between the voltage difference in terminals of the element considered and the current which crosses it, Figure2.

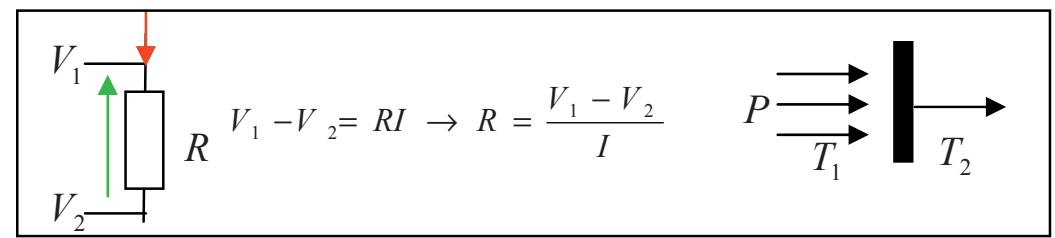

Fig.2. Simple electric and thermal resistance.

We can make an analogy to define thermal resistance. 
The thermal power to dissipate causes a rise in temperature $T_{1}$ of material and we will find a lower temperature $T_{2}$ outside this one. We conceive that as long as the thermal resistance of material is high, less it tends to yield its heat to the ambient conditions.

By the Ohm's law concept, we obtain thermal resistance as:

$$
R_{t h}=\frac{T_{1}-T_{2}}{P}
$$

Thus the unit will be $(\% / \mathrm{W})$ or $(\mathrm{K} / \mathrm{W})$

Thermal resistance is given according to:

Contact surface between materials, nature of material, and type of coating.

\section{Use in machining}

\section{Calculation of the infinite thermal resistance of the tool for milling}

The three types of heat transfer, conduction, convection and radiation, all exist in the machining operations. Heat transfer inside the chip and workpiece, the tool and tool holder is by conduction. Heat transfer between coolant/air and the chip/tool/workpiece is by convection. Radiation is rarely investigated in traditional machining operations. But radiation techniques are widely applied in measuring the temperature distribution in various machining operations $[1,6]$.

The tool for milling is compared to a cylindrical fin with an end heated who is made up of $\mathrm{N}$ infinitesimal discs, Each disc is a seat of a resistance by convection and a resistance by conduction in parallel, Figure 3. It is supposed that the not heated end is at an ambient temperature. To determine the useful temperature of the tool hot spot, it is necessary to calculate equivalent thermal resistance since the heated edge.

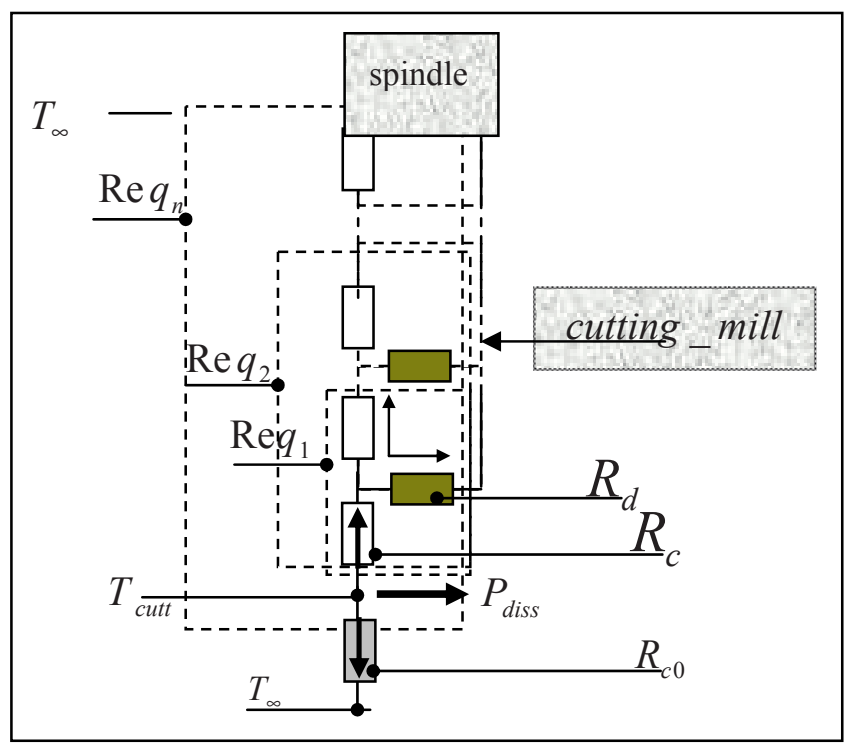

Fig.3. Thermal equivalent circuit of a cylindrical mill (flows, resistances, thermal potentials)

The fin is supposed very long and the temperature of the not heated end is $T_{\infty}$.

On Figure 3, we note:

$\square R_{d}=\frac{E_{p}}{\lambda_{C T} \cdot s_{f}} \quad \square R_{c}=\frac{1}{h \cdot S_{\text {lat }}}$

The first, second, $i^{e m e}$ and the $n^{\text {eme }}$ equivalent resistances are respectively given by: 


$$
\begin{aligned}
& R_{e q_{1}}=R_{d}+\frac{R_{d} \cdot R_{c}}{R_{d}+R_{c}} \\
& \operatorname{Re} q_{2}=R_{d}+\frac{R_{e q 1} \cdot R_{c}}{R_{e q 1}+R_{c}} \\
& \operatorname{Re} q_{i}=R_{d}+\frac{R_{e q i-1} \cdot R_{c}}{R_{e q i-1}+R_{c}} \\
& \operatorname{Re} q_{n}=R_{d}+\frac{R_{e q n-1} \cdot R_{c}}{R_{e q n-1}+R_{c}}
\end{aligned}
$$

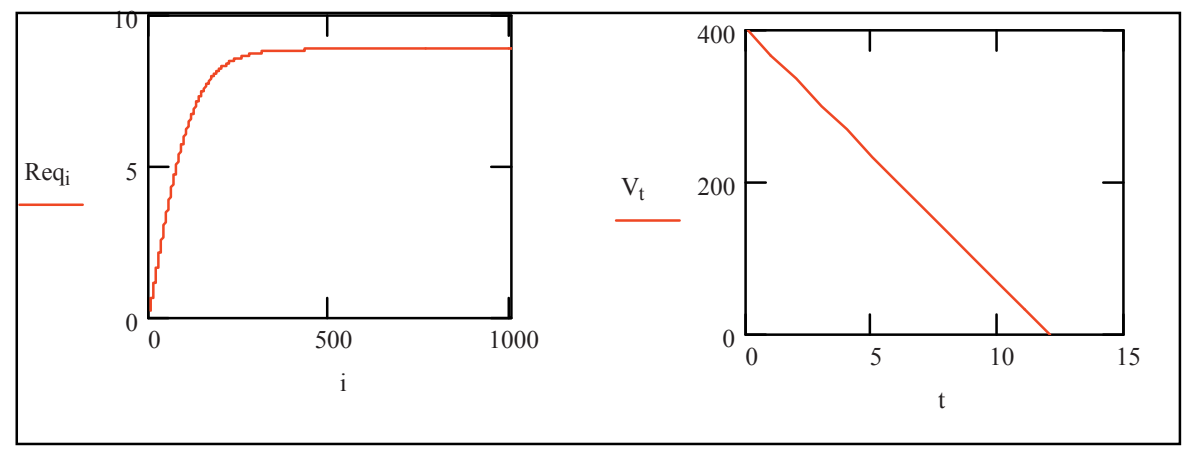

Fig.4. Convergence of equivalent resistance

Fig.5. Speed as a function of time

Figure 4 shows that the equivalent resistance converges towards a finished value, which enables us to apply easily the Ohm law's by the intermediary of the coefficient of total thermal transfer given

$$
\text { by: } K_{t o t}=\frac{1}{\operatorname{Re} q_{n}} \quad T_{\infty}=20^{\circ} \mathrm{C}
$$

$K_{\text {totale }}$ is the overall heat transfer coefficient may be obtained from the equivalent resistance, the equivalent resistance is calculated taking in account of series and parallel resistors according to Table1.

\section{Deduction of the Point Tool Temperature}

According to the Fourier law's related to the temperature gradient $[7,8]$, we have:

$$
T_{c}=K_{\text {tot }} P_{\text {diss }}+20 \quad T_{c}=685.23^{\circ} \mathrm{C}
$$

\section{Cooling of the tool edge, end of machining, expect matter}

The numerical methods were successfully applied in calculating the temperature distribution and thermal deformation in tool, chip and workpiece. Especially, the finite element and boundary element methods can deal with very complicated geometry in machining; they have great potential to solve the problems in practice $[1,2,3]$.

Due to the complex phenomenon during machining and what occurs in contact between cutting mill, chip and work part, witch depending on contact resistance and pressure, heat sources, some assumptions are imposed to calculate the cutting temperature by inverse method.

We propose to modulate the cooling of cutting mill just after milling before standstill, when the tool is out of the workpiece. 


\section{Data supposed known}

configuration, final temperature (measured), charging conditions of thermal energy storage unit, heat transfer coefficient, a decrease on cutting speed, ambient temperature, Figure5.

\section{Parameter to be determined}

The parameter to be determined is the cutting tool temperature $T_{c}$.

\section{Imposed assumptions}

- The first disc (hot spot) is at uniform temperature, is suddenly exposed to convection cooling (Hence the conduction capacity lumped method may be applied).

- The power dissipated within the first disc is dissipated into the others discs while the others discs lose heat to the air stream by convection.

- Thermal conductivity of tungsten is constant.

- Coefficient of transfer of heat by convection is related to the spindle revolutions [9].

- $\quad$ The cutting speed is decreasing during cooling, no internal generation.

- Negligible radiation exchange with surroundings, transient heat conduction.

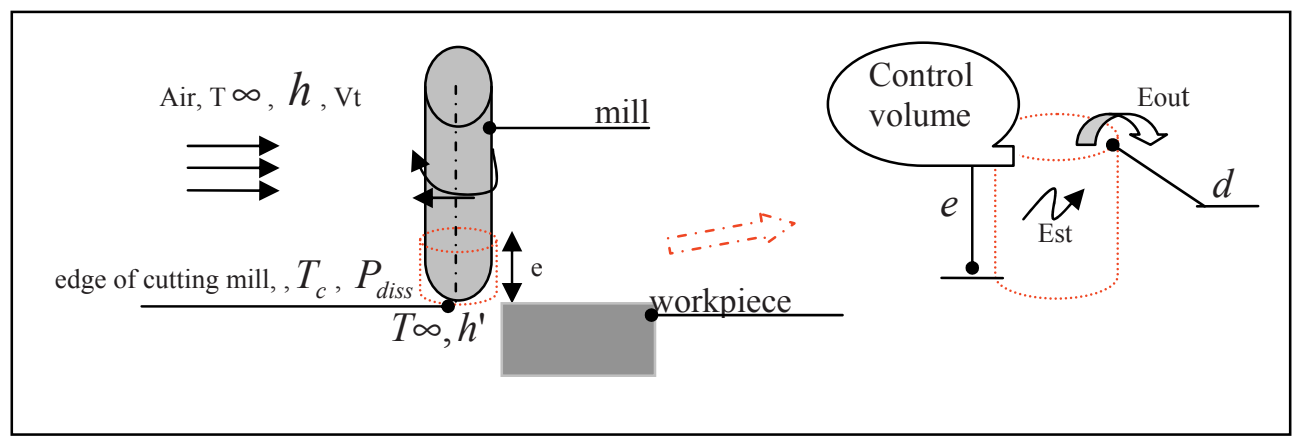

Fig.6. Transient cooling of the edge cutting mill and its energy balance

The energy balance to the control volume is given by:

$$
\begin{gathered}
E_{s t}=-E_{\text {out }} \\
E_{s t}=\rho V C \frac{\partial T}{\partial t} \text { is the rate of change of energy storage. }
\end{gathered}
$$

$E_{\text {out }}$ : Energy leaving the disc (by convection)

The preceding equation takes the differential form:

$$
C M \frac{d T}{d t}=\frac{1}{R C_{0}}(T-T \infty)+\frac{1}{R_{e q}}(T-T \infty)
$$

With initial condition:

$$
T\left(t_{f}\right)=T_{\text {meas }}
$$

Where $t_{f}$ is the duration of cooling cutting mill before time of the first relevant of temperature $T_{\text {fin }}$ measured. The thermophysics properties of cutting mill (tungsten carbide) are given below:

$$
\mathrm{C}=420 \mathrm{~J} / \mathrm{KgK} \quad \lambda_{C T}=174(\mathrm{~W} / \mathrm{mK}) \quad \rho=14500 \mathrm{Kg} / \mathrm{m}^{3}
$$

The heat transfer coefficients are given below:

$$
\begin{aligned}
& h(t)=7+12 \sqrt{\frac{V(t)}{60}} \quad h^{\prime}=15 \mathrm{~W} / \mathrm{mK} \\
& R_{c}=R_{c}(t) \text { and } \operatorname{Re} q=\operatorname{Re} q(t)
\end{aligned}
$$


451 Evaluation of the infinite thermal resistance, from equation (7):

$$
\begin{gathered}
\operatorname{Re} q_{n+1}=\operatorname{Re} q_{n} \\
\operatorname{Re} q_{n}=R_{d}+\frac{R_{C} \cdot \operatorname{Re} q_{n}}{R_{C}+\operatorname{Re} q_{n}} \\
R_{e q 2}(t)=\frac{R_{d}+\sqrt{\left[R_{d}{ }^{2}+4 R_{d} \cdot R_{c}(t)\right]}}{2}
\end{gathered}
$$

The cooling rate mill $\frac{\Delta T}{\Delta t}$ is:

$$
\left\{\begin{array}{c}
\frac{\Delta T}{\Delta t}=\frac{1}{C M}\left(\frac{1}{R_{c 0}(t)}+\frac{1}{R_{e q}(t)}\right)\left[T-T_{\infty}\right] \\
T\left(t_{f}\right)=T_{\text {meas }}
\end{array}\right.
$$

Where: $C M$ is the thermal capacitance of disc and $R_{e q t}$ and $R_{c 0}$ are the equivalent thermal resistance of the cylindrical mill and the cross convection resistance respectively.

During milling, $t<0$, there are several types of heat source: plastic work converted to heat, viscous dissipation transformed into heat, furthermore heat generated at the tool/chip interface by friction, convection through the mill area towards the air stream at $t \succ 0$.

We introduce an important factor: $\tau_{t}$ thermal constant time.

$$
\frac{1}{\tau_{t}}=\frac{1}{C M}\left(\frac{1}{R_{C 0}}+\frac{1}{R_{e q_{t}}}\right)
$$

The problem is to resolve the differential conduction equation of first order and variable constant by inverse method.

We find:

$$
\left\{\begin{array}{c}
T_{t+1}=T_{t}+1 / \tau_{t}\left(T_{t}-T_{\infty}\right) \\
T\left(t_{f}\right)=T_{\text {meas }}
\end{array}\right.
$$
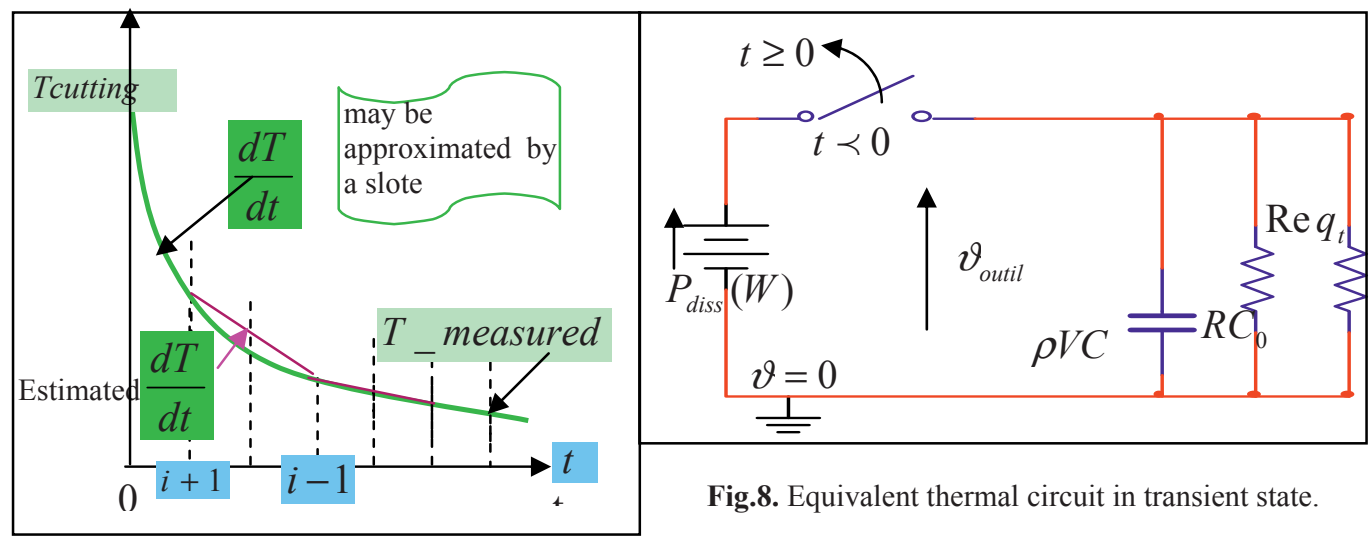

Fig.8. Equivalent thermal circuit in transient state.

Fig.7. Approximation of the cooling cutting tool curve by lines segments. 


\section{Discussion}

Figures 6 and 7 show the temperature response. When $T_{\text {meas }}$ is measured, we can plot the curve of cooling the cutting mill by equation (21) witch enables us to estimate the cutting temperature $T_{c}$ by iterations.

The spindle temperature would be higher than $T_{\infty}$ when measured by a thermocouple.

The higher the thermal constant time, the quicker the mill adapted with the new environment.

Contrary to the case of turning, then mill revolve and the workpiece relocate; heat transfer between the mill area and the air is based empirically on its rotational speed and its blows air over the surrounding (self ventilation).

\section{Conclusion}

In this paper, we have proposed a new method to modulate the mill cooling in order to extrapolate the cutting tool from the temperatures measured just when the spindle is at stand still and the temperature drop may be corrected.

This method may be applied when the hot spot temperature rise is rather difficult to measure because it has to be taken when the tool is revolving. We deduce that the temperature response as function of time is not simply linear but have an exponential form and depends on several parameters such as the rotational speed, and the thermo physical properties of mill matter.

In practice, there is a machining operation witch satisfy this condition such as boring and tapping where there is a uniform moving ring heat source and radiation exchange can not be neglected in this case.

The electrical analogy method may successfully be applied in calculating the cutting temperature and heat flow in tool, it have great potential to solve problems in practice; In this class of methods, some information such as temperatures in spindle area and in hottest spot of mill after shut down, are first obtained experimentally.

\section{References}

1. J.M. Longbottom and J.D. Lanham, 'Cutting temperature measurement while machining' Aircraft Engineering and Aerospace Technology: An International Journal 77/2 122-130, University of the West of England, Bristol, UK(2005).

2. W.Grzesik, 'Finite Difference Analysis of the Thermal Behaviour of Coated Tools in Orthogonal Cutting of Steels', International Journal of Machine Tools \& Manufacture, Department of Manufacturing and Production Automation, Technical University of Opole, Poland, 2,4, May (2004).

3. Zhang S, Liu Zhanqiang, 'Analytical and numerical Solutions of Transient Heat Conduction in Monolayer-coated Tools', Journal of M.P.T 209 (2009), School of Mechanical Engineering, Shandong University, Jinan, PR China, (2008).

4. E.Felder, 'Modélisation de la Coupe des Métaux', Technique de l'Ingénieur, BM7041, UMR 7635 CNRS-école des mines de Paris, 20, 2,13, Juillet (2006).

5. D.J. Richardson, M.A. Keavey, F. Dailami, 'Modelling of Cutting Induced Workpiece Temperatures for Dry Milling', Engineering and Mathematical Sciences, University of the West of England, Frenchay Campus, Coldharbour lane, Bristol BS16 1QY, UK, (2005).

6. M.Lazard, P.Corvisier, 'Modélisation Thermique Lors d'une Opération d'Usinage à l'aide des Fonctions de Whittaker », SFT2006, Ile de Ré, France, 16-19, 1-4-5, Mai (2006).

7. Y.Jannot, 'Transferts thermiques', Ecole des Mines de Nancy. Pages 5,24, 142, (2008).

8. Yunus, A.C, 'Heat Transfer' A Practical Approach, McGraw-Hill, Reading, NY, (2002).

9. E. Cereti, 'Ale Simulation of Orthogonal Cutting: a New Approach to Model Heat Transfer Phenomena at the Tool-Chip Interface', Annals of the CIRP 56, (2007). 